\title{
Further validation of the Multidimensional Fatigue Inventory in a US adult population sample
} Jin-Mann S Lin*1, Dana J Brimmer ${ }^{1}$, Elizabeth M Maloney ${ }^{1}$,
Ernestina Nyarko $^{1,2}$, Rhonda BeLue ${ }^{3}$ and William C Reeves ${ }^{1}$

Address: ${ }^{1}$ Chronic Viral Diseases Branch, National Center for Zoonotic, Vector-borne and Enteric Diseases, Centers for Disease Control and Prevention, Mail Stop A-15, 1600 Clifton Rd, NE, Atlanta, GA, USA, ²Department of Global Health, Rollins School of Public Health, Emory University, Atlanta, GA, USA and ${ }^{3}$ Department of Health Policy and Administration, The Pennsylvania State University, University Park, PA, USA

Email: Jin-Mann S Lin* - dwe3@cdc.gov; Dana J Brimmer - dyv4@cdc.gov; Elizabeth M Maloney - evm3@cdc.gov; Ernestina Nyarko - ernestina.nyarko@gmail.com; Rhonda BeLue - rzb10@psu.edu; William C Reeves - wcr1@cdc.gov

* Corresponding author

Published: 15 December 2009

Population Health Metrics 2009, 7:18 doi:10.1186/1478-7954-7-18
Received: 8 May 2009

Accepted: 15 December 2009

This article is available from: http://www.pophealthmetrics.com/content/7/1//8

(c) 2009 Lin et al; licensee BioMed Central Ltd.

This is an Open Access article distributed under the terms of the Creative Commons Attribution License (http://creativecommons.org/licenses/by/2.0), which permits unrestricted use, distribution, and reproduction in any medium, provided the original work is properly cited.

\begin{abstract}
Background: The Multidimensional Fatigue Inventory (MFI-20) was developed in 1995. Since then, it has been widely used in cancer research and cancer-related illnesses but has never been validated in fatiguing illnesses or in a large US population-selected sample. In this study, we sought to examine the reliability and validity of the MFI-20 in the population of the state of Georgia, USA. Further, we assessed whether the MFI-20 could serve as a complementary diagnostic tool in chronically fatigued and unwell populations.
\end{abstract}

Methods: The data derive from a cross-sectional population-based study investigating the prevalence of chronic fatigue syndrome (CFS) in Georgia. The study sample was comprised of three diagnostic groups: CFS-like (292), chronically unwell (269), and well (222). Participants completed the MFI-20 along with several other measures of psychosocial functioning, including the Medical Outcomes Survey Short Form-36 (SF-36), the Zung Self-Rating Depression Scale (SDS), and the Spielberger State-Trait Anxiety Inventory (STAl). We assessed the five MFI-20 subscales using several criteria: inter-item correlations, corrected item-total correlations, internal consistency reliability (Cronbach's alpha coefficients), construct validity, discriminant (known-group) validity, floor/ceiling effects, and convergent validity through correlations with the SF-36, SDS, and STAI instruments.

Results: Averaged inter-item correlations ranged from 0.38 to 0.61 , indicating no item redundancy. Corrected item-total correlations for all MFI- 20 subscales were greater than 0.30 , and Cronbach's alpha coefficients achieved an acceptable level of 0.70 . No significant floor/ceiling effect was observed. Factor analysis demonstrated factorial complexity. The MFI-20 also distinguished clearly between three diagnostic groups on all subscales. Furthermore, correlations with depression (SDS), anxiety (STAI), and functional impairment (SF-36) demonstrated strong convergent validity.

Conclusions: This study provides support for the MFI-20 as a valuable tool when used in chronically unwell and well populations. It also suggests that the MFI-20 could serve as a complementary diagnostic tool in fatiguing illnesses, such as CFS. 


\section{Background}

Fatigue is a common symptom associated with numerous acute and chronic illnesses. Fatigue is one of the most frequent symptoms reported to physicians; between $7 \%$ and $45 \%$ of primary care consultations involve fatigue $[1,2]$. High levels of fatigue negatively affect quality of life for patients with cancer, Parkinson's disease, multiple sclerosis, and persons with less well-understood illnesses such as chronic fatigue syndrome (CFS) and fibromyalgia [3$6]$. The fatigue associated with various conditions is generally not alleviated by rest and precludes normal mental and physical activities. Fatigue also often accompanies affective disorders [7]. Fatigue was significantly positively correlated with depression in patients with multiple sclerosis [8-10] and in patients with unexplained fatigue [11]. The national Canadian Community Health Survey reported that $36 \%$ of individuals with CFS were depressed [12], whereas a population-based study of CFS reported that $22 \%$ of individuals with CFS in Georgia had major depressive disorder, and 46\% had anxiety disorders [13]. Roy-Byrne et al. [14] found that fatigued twins were more somatically preoccupied and anxious than non-fatigued twins. Optimal management of patients with fatiguing illnesses requires assessing the nature, frequency, severity, and duration of fatigue and evaluating effects of interventions on fatigue. Although several standardized instruments have been designed to evaluate fatigue, they have not been validated across illnesses in adults.

The Multidimensional Fatigue Inventory (MFI-20) was developed by a Dutch group in 1995 to measure fatigue severity [2]. The MFI-20 was first evaluated in a group of people with CFS, cancer patients, a healthy control group comprised of psychology and medical students, and a group of army recruits [2]. The MFI-20 showed good internal consistency (Cronbach's alpha > 0.80) for the general, physical, and mental fatigue dimensions, and adequate reliability for the reduced activity and motivation items (Cronbach's alpha $>0.65$ ). Construct validity between the different test groups was significant at $\mathrm{p}<0.001$ for all five dimensions. Convergent validity between the MFI-20 and the Visual Analogue Scale (VAS) fatigue score for the group of cancer patients was significant for all subscales.

Validity and reliability of the MFI-20 have also been evaluated in several other non-US populations. These included patients with cancer [15-17], chronic fatigue $[3,18]$, craniopharyngioma [19], myelodysplastic patients [20], thyroid disease, and a "not tired" control group [18].

Test-retest reliability of the MFI-20 has been reported in several European studies. Ericsson and Mannerkorpi validated the MFI-20 in 166 Swedish patients with fibromyalgia and chronic widespread pain [3]. Hagelin et al. [17] validated the MFI-20 in four groups composed of 584
Swedish subjects: palliative cancer patients, cancer patients receiving radiation therapy, noncancer outpatients, and a group of hospital staff. Gentile et al. [18] validated the MFI-20 in three groups of French subjects: tired, (82 subjects), moderately tired (36), and not tired (107). Finally, Schwarz et al. [21] published the population norms for the five MFI-20 subscales in a sample of 2,037 adult Germans. The crucial result of the Schwarz study was the quantification of age and sex dependency in fatigue.

In the United States, Schneider validated the MFI-20 in 97 rural oncology outpatients and in 45 spouses or firstdegree female caregivers of male hemodialysis patients in northern and eastern Iowa [22,23]. To our knowledge, the MFI-20 has not been validated in persons from the US with fatiguing illnesses nor in a large US populationselected sample. The aims of the present study were: 1) to investigate the reliability and validity of the MFI-20 in chronically unwell and well persons; 2) and to assess whether the MFI-20 could serve as a complementary diagnostic tool in populations with fatiguing illnesses.

\section{Methods}

The data came from a cross-sectional, population-based study investigating the prevalence of CFS in Georgia. Details of the source study have been previously published [24] but are summarized here. The Centers for Disease Control and Prevention (CDC) Institutional Review Board, as required by US Department of Health and Human Services regulations, approved the study. All participants provided informed consent.

\section{Study design and sample}

The study was carried out in two phases between September 2004 and July 2005. Phase 1 involved a random-digitdialing telephone survey to screen 19,381 adult residents ( $96 \%$ response) ages 18 to 59 from metropolitan, urban, and rural Georgia populations. Based on the 19,381 people from the household screening interview, 8,910 adults were randomly selected for detailed telephone interviews: 5,623 individuals completed the detailed telephone interview; 1,874 refused to participate; 141 were further confirmed to be ineligible; and 1,272 were excluded due to physical or mental inability to participate, inability to be contacted, language barriers, or because they had died. This yielded an overall response rate of $75 \%$. Based on the detailed telephone interviews, study participants were classified into three groups:

1) CFS-like, characterized by severe fatigue lasting six months or longer that was not alleviated by rest, that caused substantial reduction in occupational, educational, social, or personal activities, and that was accompanied by at least four of the CFS case-defining symptoms. 
2) Chronically unwell, having chronic ( $\geq$ six months) unwellness with or without fatigue, but not meeting the criteria for CFS.

\section{3) Well.}

In Phase 2, all 469 people with CFS-like illness were invited for clinical evaluation, and 292 (62\%) participated. Of randomly selected chronically unwell participants, 286 (53\%) completed the clinical evaluation. Finally, 223 individuals classified as well in the telephone interview completed clinical evaluations. They were matched to the CFS-like group based on residence (metropolitan, urban, rural), sex, race/ethnicity, and age (within three years). Overall, about $50 \%$ of invited respondents from all three groups completed the one-day clinical evaluation.

Participants completed the MFI-20 and other questionnaires during the clinical evaluation. This study involves data from 783 participants who completed the MFI-20 along with several other measures of psychosocial functioning, including the Medical Outcomes Survey Short Form-36 (SF-36), the Zung Self-Rating Depression Scale (SDS), and the Spielberger State-Trait Anxiety Inventory (STAI).

\section{Measures}

\section{MFI-20 Subscales}

The MFI-20 comprises five subscales: general fatigue, physical fatigue, mental fatigue, reduced activity, and reduced motivation [2]. Each subscale includes four items with five-point Likert scales. General fatigue includes general statements about fatigue and decreased functioning and was designed to encompass both physical and psychological aspects of fatigue. Physical fatigue concerns physical sensations related to fatigue. Mental fatigue pertains to cognitive functioning, including difficulty concentrating. Reduced activity refers to the influence of physical and psychological factors on the level of activity. Reduced motivation relates to lack of motivation for starting any activity. Scores on each subscale range from 4 to 20, with higher scores indicating greater fatigue.

\section{SF-36 Subscales}

The SF-36 contains eight multi-item subscales: general health perceptions, physical functioning, role physical (role limitations due to physical problems), bodily pain, general mental health, vitality (vitality/energy/fatigue), role emotional (role limitations due to emotional problems), and social functioning. The number of response choices per item ranges from two to six. Each transformed subscale has a range from 0 to $100(100=$ optimal function) [25]. The SF-36 also yields two summary scores that reflect the two-dimensional factor structure underlying the eight subscales: a physical component summary (PCS) score and a mental component summary (MCS) score. PCS and MCS are a linear combination of eight SF36 subscales, but PCS is predominantly based on the subscales physical functioning, role physical, bodily pain, and general health perceptions, and MCS is predominantly based on the scales mental health, role emotional, social functioning, and vitality (range $0-100,100=$ optimal) [26].

\section{SDS Subscale}

The SDS [27] includes 20 questions that quantify the severity of depression symptoms. Each item ranges from 1 (none or a little of the time) to 4 (most or all of the time). The raw SDS score is the sum of all 20 items and ranges from 20 to 80 . Following standard practice, we converted raw SDS scores to a 100-point scale (SDS index) in which $<50=$ normal, $50-59=$ mild depression, $60-69=$ moder ate to marked depression, and $\geq 70=$ severe depression.

\section{STAI Subscales}

The STAI [28] includes 40 questions with four possible responses to each. It was constructed as two subscales: 20 items to assess state anxiety, and another 20 to assess trait anxiety. State anxiety is defined as a transient, momentary emotional status that results from situational stress. Trait anxiety represents a predisposition to react with anxiety in stressful situations. Each subscale ranges from 20 to 80, with higher scores indicating higher anxiety. These two parts differ in the item wording, in the response format (intensity versus frequency), and in the instructions for how to respond. The STAI clearly differentiates between the temporary condition of state anxiety and the more general and long-standing quality of trait anxiety.

All four questionnaires were self-reported and self-administered by participants. The mean time taken to complete each questionnaire was five, nine, three, and four minutes for the MFI-20, SF-36, SDS, and STAI, respectively. The Flesch Reading Ease formula and a Flesch abstraction formula were applied. The measures are generally shown to be useful for respondents with a sixth grade reading level or below. The reading level of each respondent was assessed by the Wide Range Achievement Test reading subtest [29], and only 45 (6\%) of respondents were below a sixth grade reading level.

\section{Statistical analysis}

We used SAS version 9.1 (SAS Institute Inc, Cary, NC) for data analysis. Descriptive statistics (frequencies, percentages, means, standard deviations, and ranges) were generated to characterize the study sample in terms of sociodemographic parameters. We used several criteria to assess the subscale validity and reliability of the MFI- 20 . 
Internal consistency of each of the five MFI-20 subscales was determined using three reliability tests: 1 ) inter-item correlation; 2) corrected-to-total (or item-total) subscale correlation; 3) and Standardized Cronbach's $\alpha$ coefficients (and item discrimination). The cutoff criteria for acceptance on reliability tests are as follows. First, itemtotal subscale correlations of not less than 0.30 and interitem correlations of 0.30 to 0.70 were retained. Second, a fairly high reliability coefficient (Cronbach's $\alpha>0.70$ ) was required to assess the internal consistency reliability $[30,31]$. Floor/ceiling effects were considered significant if more than $15 \%$ of the subjects had either the lowest possible or highest possible score on the subscales [32]. A significant floor effect was expected in the well group.

As an indication of discriminant (known-group) validity, group differences in the five MFI-20 subscales were calculated using analyses of variance to examine the ability of the MFI-20 instrument to distinguish three groups: CFSlike, chronically unwell, and well. Using a Tukey correction, the alpha per test for each subscale was 0.01 , for an overall alpha of 0.05 . Two-way analyses of variance were performed to test the age and sex effects on the five MFI20 subscales. Post-hoc analysis with Tukey p-value adjustment was performed for multiple subgroup comparisons.

To further assess construct validity of the subscales, an exploratory factor analysis was performed. A principle component analysis was used to extract factors. The obtained factors were rotated oblique using the Varimax procedure. A minimum eigenvalue of 1 was specified as the extraction criterion [33]. The desired criterion of factor loadings was set at 0.50 or above, slightly higher than the typical cutoff value of 0.40 [34].

Finally, the convergent validity of the MFI-20 was evaluated through comparisons of the MFI-20 with other instruments administered in the protocol. Pearson correlation coefficients were used to assess linear associations between the multi-item scales of SF-36, SDS, and STAI. We chose these instruments based on the association between fatigue and other measures on psychosocial functioning, such as health-related quality of life (measured by SF-36), depression (measured by SDS), and anxiety (measured by STAI) as well as the existing data from the source study.

The most valid SF-36 subscales for measuring physical health include the physical functioning, role physical, and bodily pain subscales and the physical component summary score [26]. The most valid SF-36 subscales for measuring mental health include the mental health, role emotional, and social functioning subscales and the mental component summary score [26]. For the concept of physical and mental health, we investigated correlations between MFI-20 subscales and physical and mental health as measured by the SF-36.

\section{Results}

Data completeness was high, with only one missing response for the reduced activity subscale among all five subscales. This indicated that the MFI-20 was wellaccepted in our study sample of chronically unwell and well people.

\section{Sample characteristics}

Table 1 summarizes subscale validity and reliability analyses for the 783 participants who completed the MFI-20 questionnaire. Of these, $37 \%$ had been classified as CFSlike based on the detailed telephone interview, 34\% were chronically unwell, and $28 \%$ were considered well. The participants had a mean age of 43 , were primarily female $(76 \%)$, white $(70 \%)$, and from rural or urban areas (83\%). Nearly $95 \%$ had completed at least a high school education. Nearly 38\% were unemployed, self-employed (not working for pay), retired, laid off, disabled, or students. More than $60 \%$ of participants were married or cohabitating. More than half of participants had a household income equal to or higher than the Georgia median income level of $\$ 42,679$.

\section{Associations of age and sex with MFI-20 subscale scores}

Only the physical fatigue subscale score differed significantly by both age $(p=0.0024)$ and sex $(p=0.0015)$. Reduced activity $(\mathrm{p}=0.0078)$ and reduced motivation $(\mathrm{p}$ $=0.0112$ ) scores differed significantly between age groups. General fatigue $(\mathrm{p}=0.0003)$ and mental fatigue $(p=0.0272)$ scores were significantly worse in females than in males. The interaction between age and sex was not significant in any of the MFI-20 subscales. Although only three of the five MFI-20 subscales were significantly different by sex, descriptive statistics of all the subscales were summarized for females and males (Table S1 and Table S2, Additional file 1).

For subscales with significant age or sex effects, we estimated partial correlations controlling for sex and age, respectively (Table 2). This had negligible effects on the correlations between the physical fatigue, reduced activity, and reduced motivation subscales.

\section{Reliability}

Table 3 summarizes the results of three reliability tests for the five MFI-20 subscales. There was no item redundancy; inter-item correlations averaged 0.56 (range 0.46-0.69) for general fatigue, 0.52 (range 0.44-0.61) for physical fatigue, 0.53 (0.41-0.66) for reduced activity, 0.38 (0.17$0.56)$ for reduced motivation, and 0.61 (0.53-0.66) for mental fatigue. Corrected item-total correlations were higher than 0.30 for all five MFI-20 subscales. The values 
Table I: Characteristics of the study sample

\begin{tabular}{|c|c|c|c|}
\hline Characteristic & $\begin{array}{r}\text { CFS-like } \\
(n=292,37.29 \%)\end{array}$ & $\begin{array}{r}\text { Chronically Unwell } \\
(n=269,34.36 \%)\end{array}$ & $\begin{array}{r}\text { Well } \\
(n=222,28.35 \%)\end{array}$ \\
\hline Age, yrs, Mean (SD) & $43.73(9.87)$ & 43.05 (11.24) & $43.68(9.96)$ \\
\hline \multicolumn{4}{|l|}{ Sex**** } \\
\hline Female & $243(83.22 \%)$ & $170(63.43 \%)$ & $184(82.51 \%)$ \\
\hline Male & $49(16.78 \%)$ & $98(36.57 \%)$ & 39 (17.49\%) \\
\hline \multicolumn{4}{|l|}{ Race** } \\
\hline Black & $65(22.26 \%)$ & $84(31.34 \%)$ & $48(21.52 \%)$ \\
\hline White & 208 (7I.23\%) & 173 (64.55\%) & $170(76.23 \%)$ \\
\hline All Others & $19(6.51 \%)$ & II (4.10\%) & $5(2.24 \%)$ \\
\hline \multicolumn{4}{|l|}{ Geographic Areas } \\
\hline Metropolitan & $43(14.73 \%)$ & $56(20.90 \%)$ & $33(14.80 \%)$ \\
\hline Urban & $108(36.99 \%)$ & $78(29.10 \%)$ & $81(36.32 \%)$ \\
\hline Rural & |4| (48.29\%) & $134(50.00 \%)$ & $109(48.88 \%)$ \\
\hline \multicolumn{4}{|l|}{ Educational Status $* * * *$} \\
\hline$<$ High School & $23(7.88 \%)$ & $15(5.60 \%)$ & $7(3.14 \%)$ \\
\hline High School Graduate/GED & 75 (25.68\%) & $52(19.40 \%)$ & $33(14.80 \%)$ \\
\hline Trade, Technical, or Vocation School after High School & $30(10.27 \%)$ & $44(16.42 \%)$ & $24(10.76 \%)$ \\
\hline Some College & $68(23.29 \%)$ & $49(18.28 \%)$ & $47(21.08 \%)$ \\
\hline 2-yr College Graduate or Higher & $95(32.53 \%)$ & 107 (39.93\%) & $112(50.22 \%)$ \\
\hline Missing & I $(0.34 \%)$ & I $(0.37 \%)$ & $0(0.00 \%)$ \\
\hline \multicolumn{4}{|l|}{ Marital Status } \\
\hline Married/living together & $184(63.01 \% \%)$ & $168(62.69 \%)$ & $15 \mid(67.71 \%)$ \\
\hline Single/widowed/divorced/seperated & 107 (36.64\%) & $100(37.31 \%)$ & $72(32.29 \%)$ \\
\hline Missing & I $(0.34 \%)$ & $0(0.00 \%)$ & $0(0.00 \%)$ \\
\hline \multicolumn{4}{|l|}{ Employment Status $* * * *$} \\
\hline Full Time: $>=30$ hours/week & $16 \mid(55.14 \%)$ & $167(62.31 \%)$ & $159(71.30 \%)$ \\
\hline Part Time: $<30$ hours/week & $31(10.62 \%)$ & $26(9.70 \%)$ & $23(10.31 \%)$ \\
\hline Self-employed & $2(068 \%)$ & $0(0.00 \%)$ & $2(0.90 \%)$ \\
\hline Not employed & $16(5.48 \%)$ & $23(8.58 \%)$ & $3(1.35 \%)$ \\
\hline Retired & $2(0.68 \%)$ & $6(2.24 \%)$ & $9(4.04 \%)$ \\
\hline Laid off & $4(1.37 \%)$ & $6(2.24 \%)$ & $2(0.90 \%)$ \\
\hline Disabled & $45(15.41 \%)$ & $17(6.34 \%)$ & $2(0.90 \%)$ \\
\hline Homemaker & $20(6.85 \%)$ & 14 (5.22\%) & 17 (7.62\%) \\
\hline Student & $10(3.42 \%)$ & $9(3.36 \%)$ & $6(2.69 \%)$ \\
\hline Missing & I (0.34\%) & $0(0.00 \%)$ & $0(0.00 \%)$ \\
\hline \multicolumn{4}{|l|}{ Income* } \\
\hline$>=$ GA Median Income & 146 (50.00\%) & $|4|(52.61 \%)$ & $142(63.68 \%)$ \\
\hline$<$ GA Median Income & I 33 (45.55\%) & 117 (43.66\%) & 75 (33.63\%) \\
\hline Missing & $13(4.45 \%)$ & $10(3.73 \%)$ & $6(2.69 \%)$ \\
\hline
\end{tabular}

All values are No. (\%) unless other indicated. †Column percentage

for standardized Cronbach's $\alpha$ for the five MFI-20 scales were: general fatigue: 0.83 ; physical fatigue: 0.81 ; reduced activity: 0.82; reduced motivation: 0.71 ; and mental fatigue: 0.86 . These values were greater than the suggested criteria value of 0.70 for acceptable reliability.

\section{Relationships among five MFI-20 subscales}

Pairwise correlations between the MFI-20 subscales ranged from 0.49 to 0.74 . Although the subscales are strongly related to each other, it is unclear whether an overall summary component of the MFI-20 is appropriate. Factor analysis confirmed that overall summary components accounted for $70 \%$ of the reliable variance in the five subscales. The total scale with 20 items yielded a
Cronbach's $\alpha$ coefficient of 0.93 , which is consistent with the result from the Gentile study [18].

The factor analysis solution was complex, with multiple loadings of items having factor-loading values $>0.50$ across five factors (Table 4). However, the first factor, which explained $20 \%$ of the variance in the 20 items of the MFI-20, was dominated by general fatigue and physical fatigue. Six items (four physical fatigue, one general fatigue, and one reduced activity) loaded on the first factor (loadings from 0.54 to 0.83 ). The second factor was comprised solely of all four mental fatigue items (loadings from 0.71 to 0.81 ), which explained $15 \%$ of the variance in the 20 items of the MFI-20. Three of the reduced 
Table 2: Correlations among MFI-20 subscales and their partial correlations controlled for age or sex.

\begin{tabular}{llll}
\hline Age Effect & & & Reduced Motivation \\
\cline { 2 - 4 } & Physical Fatigue & Reduced Activity & 0.6301 \\
\hline $\begin{array}{l}\text { Physical Fatigue } \\
\text { Reduced Activity }\end{array}$ & $\mathbf{0 . 6 7 3 8}$ & 0.6777 & 0.6893 \\
\hline Reduced Motivation & $\mathbf{0 . 6 2 5 5}$ & $\mathbf{0 . 6 8 5 5}$ & \\
\hline Sex Effect & & & Mental Fatigue \\
\cline { 2 - 4 } & Physical Fatigue & General Fatigue & 0.4933 \\
\hline $\begin{array}{l}\text { Physical Fatigue } \\
\text { General Fatigue }\end{array}$ & $\mathbf{0 . 7 3 5 6}$ & 0.7392 & 0.5940 \\
Mental Fatigue & $\mathbf{0 . 4 8 9 1}$ & $\mathbf{0 . 5 9 0 4}$ & \\
\hline
\end{tabular}

Note: upper right triangle: Pearson correlations; lower left triangle (numbers in Italic and bold): partial correlations (controlled for sex and age, respectively). All p-values are $<0.0001$.

activity items fell nicely (loading from 0.52 to 0.71 ) on the third factor. The fourth factor was loaded by three of the general fatigue items (loading from 0.52 to 0.71 ) and two of the reduced motivation items (loading 0.58 and $0.64)$. The remaining two reduced motivation items fell nicely on the fifth factor.

\section{Discriminant (known-group) validity: MFI-20 subscale differences between three groups}

The CFS-like, chronically unwell, and well groups had significantly different mean values $(\mathrm{p}<0.0001)$ for all the MFI-20 subscales (Table 5). All subscales appeared to discriminate between groups, but the degree to which they discriminated varied. The CFS-like group had higher scores in all the subscales compared to the chronically unwell group (average mean difference $=2.90$; range of mean difference: 2.26 points (reduced activity) - 3.54 points (general fatigue). Compared to the well group, the CFS-like group had subscale scores that were, on average, 6.01 points higher. Mean differences between these groups ranged from 4.56 points (reduced activity) to 7.96 points (general fatigue), whereas the chronically unwell group scored, on average, 3.11 points higher in the five subscales than the well group.

We observed a floor/ceiling effect in all the MFI-20 subscales in the well group, except for general fatigue, as expected. No floor/ceiling effects were detected in the CFS-like and chronically unwell groups. There were no floor/ceiling effects in the whole study sample (Table 5).

\section{Convergent validity: relationships to functional impairment, depression, and anxiety}

We calculated correlations between fatigue subscales and subscales measuring functional impairment (SF-36), depression (SDS), and anxiety (STAI) to evaluate convergent validity in the overall sample (Table 6). The MFI-20 subscales were substantially correlated with the eight SF36 subscales (average: $\mathrm{r}=-0.53$; range of absolute values of correlations: $|\mathrm{r}|=0.34-0.83)$. All MFI-20 subscales were most strongly correlated [35] with the SF-36 subscales measuring vitality (average: $r=-0.68$; range of $|r|$ : $0.57-0.83$ ), followed by general health perception (average: $r=-0.59$; range of $|r|: 0.48-0.71)$, and social functioning (average: $\mathrm{r}=-0.54$; range of $|\mathrm{r}|: 0.50-0.59$ ).

Table 3: MFI-20 scale item characteristics and internal consistency reliabilities.

\begin{tabular}{|c|c|c|c|c|c|c|}
\hline & & & $\begin{array}{l}\text { Inter-item } \\
\text { correlation }\end{array}$ & $\begin{array}{r}\text { Corrected-to-total } \\
\text { correlation }\end{array}$ & $\begin{array}{r}\text { Coefficient } \alpha \text { if item } \\
\text { deleted }\end{array}$ & $\begin{array}{r}\text { Standardized } \\
\text { Cronbach's }\end{array}$ \\
\hline & Mean & SD & Mean (Range) & Range & Range & $\alpha$ \\
\hline General Fatigue & 12.90 & 4.68 & $0.56(0.46-0.69)$ & $0.59-0.70$ & $0.77-0.84$ & 0.83 \\
\hline Physical Fatigue & 10.85 & 4.36 & $0.52(0.44-0.61)$ & $0.59-0.67$ & $0.75-0.79$ & 0.81 \\
\hline Reduced Activity & 9.25 & 4.16 & $0.53(0.4 I-0.66)$ & $0.5|-0.7|$ & $0.75-0.84$ & 0.82 \\
\hline Reduced Motivation & 9.58 & 3.90 & $0.38(0.17-0.56)$ & $0.33-0.62$ & $0.57-0.75$ & 0.71 \\
\hline Mental Fatigue & 10.95 & 4.54 & $0.61(0.53-0.66)$ & $0.68-0.75$ & $0.81-0.84$ & 0.86 \\
\hline Total Fatigue Score & 53.53 & 17.93 & $0.40(0.11-0.68)$ & $0.33-0.77$ & $0.92-0.93$ & 0.93 \\
\hline
\end{tabular}


Table 4: Factor analysis of $20 \mathrm{MFI}$ item responses.

\begin{tabular}{|c|c|c|c|c|c|}
\hline & \multicolumn{5}{|c|}{ Five Factors } \\
\hline & $\mathbf{I}$ & 2 & 3 & 4 & 5 \\
\hline \multicolumn{6}{|l|}{ General Fatigue } \\
\hline I feel fit & .83 & & & & \\
\hline I feel tired & & & & .71 & \\
\hline I feel rested & & & & .52 & \\
\hline I tired easily & & & & .61 & \\
\hline \multicolumn{6}{|l|}{ Physical Fatigue } \\
\hline Physically I feel I am in an excellent condition & .81 & & & & \\
\hline Physically I feel I am in a bad condition & .67 & & & & \\
\hline Physically I can take on a lot & .56 & & & & \\
\hline Physically I feel only able to do a little & .54 & & & & \\
\hline \multicolumn{6}{|l|}{ Reduced Activity (Vigor) } \\
\hline I think I do very little in a day & & & .84 & & \\
\hline I think I do a lot in a day & & & .78 & & \\
\hline I get little done & & & .72 & & \\
\hline I feel very active & .68 & & & & \\
\hline \multicolumn{6}{|l|}{ Reduced Motivation } \\
\hline I have a lot of plans & & & & & .89 \\
\hline I feel like doing all sorts of nice things & & & & & .53 \\
\hline I dread having to do things & & & & .64 & \\
\hline I don't feel like doing anything & & & & .58 & \\
\hline \multicolumn{6}{|l|}{ Mental Fatigue (Cognition) } \\
\hline When I am doing something, I can keep my thoughts on it & & .81 & & & \\
\hline I can concentrate well & & .81 & & & \\
\hline My thoughts easily wander & & .75 & & & \\
\hline It takes a lot of effort to concentrate on things & & .71 & & & \\
\hline Total \% of Variance Explained & 20.10 & 15.18 & 14.10 & 13.40 & 6.87 \\
\hline
\end{tabular}

Note: Factor loadings less than 0.5 were not listed in the table. The numbers in bold indicated the largest factor loading of the item loaded on different factor components.

Kaiser-Meyer-Olkin $(\mathrm{KMO})=0.938$, p-value for Bartlett's Test of Sphericity is $<0.001$. Cumulative \% of Variance Explained is $70 \%$.

As expected, all five MFI-20 subscales were significantly correlated with depression, anxiety, and functional impairment. However, the correlations with depression and anxiety were generally lower (average: $\mathrm{r}=0.50$; range of $r=0.34-0.65)$ than correlations with functional impairment (the SF-36 subscales). The highest correlations were found between MFI-20 subscales and measurement of depression (SDS index) (average: $\mathrm{r}=0.58$; range of $\mathrm{r}=$ $0.50-0.65)$.

\section{Conceptual relationship: Mental and Physical}

The general fatigue subscale of the MFI-20 was associated with both physical and mental health, based on strong correlations $(|\mathrm{r}|>=0.5)$ with functional impairment as measured by the SF-36 subscales (except for physical functioning, bodily pain, and role emotional), and both the physical component summary score and mental component summary score. General fatigue was also highly associated with the SDS index and the STAI trait-anxiety subscale.

The physical fatigue subscale of the MFI-20 was highly correlated $(|r|>=0.5)$ with several subscales of the SF-36 that measure predominantly physical health (physical functioning, role physical, bodily pain, social functioning, vitality, general health) and the physical component summary score but not the mental component summary score (Table 6). Physical fatigue was also highly correlated with the SDS index score measuring depression.

The mental fatigue subscale of the MFI-20 was highly correlated with several subscales of the SF-36 that measure predominantly mental health (social functioning, mental health, and vitality subscales), as well as the mental component summary score. The mental fatigue subscale was also associated with depression (SDS index) and trait anxiety (STAI).

The reduced activity subscale of the MFI-20 was highly correlated $(|\mathrm{r}|>=0.5)$ with several SF-36 subscales (physical functioning, social functioning, vitality, and general health perception). The reduced motivation subscale of the MFI-20 was highly correlated with many SF-36 subscales (role physical, social functioning, mental health, and vitality) as well as the mental component summary measure, but not the physical component score. Reduced 
Table 5: Descriptive statistics for the five MFI-20 scales by subgroups

\begin{tabular}{|c|c|c|c|c|}
\hline & All & CFS-like & Chronically Unwell & Well \\
\hline \multicolumn{5}{|c|}{ General Fatigue } \\
\hline Mean & 12.90 & 16.38 & 12.84 & 8.42 \\
\hline SD & 4.68 & 2.73 & 3.93 & 3.59 \\
\hline $25 \%$ & 9.00 & 15.00 & 10.00 & 6.00 \\
\hline Median & 14.00 & 17.00 & 13.00 & 8.00 \\
\hline $75 \%$ & 17.00 & 18.00 & 16.00 & 11.00 \\
\hline Range & $4-20$ & $6-20$ & $4-20$ & $4-20$ \\
\hline$\%$ at floor & 3.45 & 0 & 1.49 & 10.31 \\
\hline$\%$ at ceiling & 6.13 & 13.01 & 3.36 & 0.45 \\
\hline \multicolumn{5}{|c|}{ Physical Fatigue } \\
\hline Mean & 10.85 & 13.63 & 10.39 & 7.77 \\
\hline SD & 4.36 & 3.79 & 3.76 & 3.36 \\
\hline $25 \%$ & 7.00 & 11.00 & 8.00 & 5.00 \\
\hline Median & 11.00 & 14.00 & 10.00 & 7.00 \\
\hline $75 \%$ & 14.00 & 16.00 & 13.00 & 10.00 \\
\hline Range & $4-20$ & $4-20$ & $4-20$ & $4-19$ \\
\hline$\%$ at floor & 6.39 & 0.34 & 5.60 & 15.25 \\
\hline$\%$ at ceiling & 2.81 & 6.51 & 1.12 & 0 \\
\hline \multicolumn{5}{|c|}{ Reduced Activity } \\
\hline Mean & 9.25 & I I.32 & 9.06 & 6.76 \\
\hline SD & 4.16 & 4.37 & 3.75 & 2.67 \\
\hline $25 \%$ & 6.00 & 8.00 & 6.00 & 5.00 \\
\hline Median & 8.00 & 11.00 & 8.00 & 6.00 \\
\hline $75 \%$ & 12.00 & 15.00 & 12.00 & 8.00 \\
\hline Range & $4-20$ & $4-20$ & $4-20$ & $4-16$ \\
\hline$\%$ at floor & 11.49 & 3.77 & 8.96 & 24.66 \\
\hline$\%$ at ceiling & 2.43 & 5.14 & 1.49 & 0 \\
\hline \multicolumn{5}{|c|}{ Reduced Motivation } \\
\hline Mean & 9.58 & 11.95 & 9.29 & 6.82 \\
\hline SD & 3.90 & 3.53 & 3.35 & 2.91 \\
\hline $25 \%$ & 6.00 & 9.50 & 7.00 & 4.00 \\
\hline Median & 9.00 & 12.00 & 9.00 & 6.00 \\
\hline $75 \%$ & 12.00 & 14.00 & 11.00 & 8.00 \\
\hline Range & $4-20$ & $4-20$ & $4-20$ & $4-20$ \\
\hline$\%$ at floor & 11.49 & 1.37 & 10.07 & 26.46 \\
\hline$\%$ at ceiling & 0.77 & 1.37 & 0.37 & 0.45 \\
\hline \multicolumn{5}{|c|}{ Mental Fatigue } \\
\hline Mean & 10.95 & 13.77 & 10.98 & 7.23 \\
\hline SD & 4.54 & 3.77 & 4.00 & 3.07 \\
\hline $25 \%$ & 7.00 & 11.50 & 8.00 & 4.00 \\
\hline Median & 11.00 & 14.00 & 11.00 & 7.00 \\
\hline $75 \%$ & 14.00 & 17.00 & 14.00 & 9.00 \\
\hline Range & $4-20$ & $4-20$ & $4-20$ & $4-20$ \\
\hline$\%$ at floor & 9.96 & 1.37 & 6.34 & 25.56 \\
\hline$\%$ at ceiling & 3.70 & 7.19 & 2.61 & 0.45 \\
\hline
\end{tabular}

activity was also correlated with depression (SDS index) and anxiety (STAI trait-anxiety).

We examined the total fatigue score of the MFI-20 in relation to other instruments. Total fatigue was highly correlated with all SF-36 subscales except for bodily pain, and was correlated with the physical component summary score and mental component summary score, as well as SDS index and state-anxiety and trait-anxiety subscales (STAI). The total fatigue score of the MFI-20 was highly consistent and demonstrated the highest correlations with other questionnaires.

Relationships to depression, anxiety, and functional impairment among classification groups

In the CFS-like group, the SF-36 subscale scores were highly correlated with the MFI-20 subscales for general fatigue, physical fatigue, reduced activity, and reduced motivation but not with mental fatigue. Also in this group, depression (SDS index) was highly correlated with 
Table 6: Convergent Validity: Pearson Correlation Coefficients between the MFI-20, SF-36, SDS, and STAIt in overall sample.

\begin{tabular}{|c|c|c|c|c|c|c|}
\hline & \multicolumn{6}{|c|}{ MFI-20 } \\
\hline & $\begin{array}{l}\text { General } \\
\text { Fatigue }\end{array}$ & $\begin{array}{l}\text { Physical } \\
\text { Fatigue }\end{array}$ & $\begin{array}{l}\text { Reduced } \\
\text { Activity }\end{array}$ & $\begin{array}{l}\text { Reduced } \\
\text { Motivation }\end{array}$ & $\begin{array}{l}\text { Mental } \\
\text { Fatigue }\end{array}$ & $\begin{array}{l}\text { Total } \\
\text { Score }\end{array}$ \\
\hline \multicolumn{7}{|l|}{ SF-36 } \\
\hline Physical Functioning & -0.496 & -0.643 & -0.522 & -0.490 & -0.376 & -0.564 \\
\hline Role Physical & -0.591 & -0.589 & -0.464 & -0.502 & -0.429 & -0.599 \\
\hline Bodily Pain & -0.498 & -0.546 & -0.386 & -0.390 & -0.338 & -0.486 \\
\hline Social Functioning & -0.553 & -0.535 & -0.506 & -0.592 & -0.500 & -0.645 \\
\hline Mental Health & -0.547 & -0.461 & -0.436 & -0.564 & -0.550 & -0.631 \\
\hline Role Emotional & -0.462 & -0.409 & -0.379 & -0.435 & -0.480 & -0.530 \\
\hline Vitality & -0.825 & -0.689 & -0.582 & -0.708 & -0.574 & $-0.8 I I$ \\
\hline General Health & -0.659 & -0.713 & -0.533 & -0.562 & -0.479 & -0.672 \\
\hline PCS $\ddagger$ & -0.540 & $-0.67 \mid$ & -0.492 & -0.450 & -0.327 & -0.544 \\
\hline MCS $\ddagger$ & -0.563 & -0.448 & -0.455 & -0.589 & -0.563 & -0.653 \\
\hline \multicolumn{7}{|l|}{ SDS } \\
\hline SDS Index & 0.626 & $0.54 I$ & 0.498 & 0.649 & 0.608 & 0.718 \\
\hline \multicolumn{7}{|l|}{ STAI } \\
\hline State-Anxiety Score & 0.413 & 0.352 & 0.336 & 0.457 & 0.469 & 0.503 \\
\hline Trait-Anxiety Score & 0.519 & 0.421 & 0.423 & 0.558 & 0.563 & 0.620 \\
\hline
\end{tabular}

All p-values for pairwise Pearson correlations are less than $0.000 \mathrm{I}$

Absolute correlation coefficients of 0.5 to 1.0 [35] are considered high correlations, in bold.

† Multidimensional Fatigue Inventory (MFI-20), the Medical Outcomes Survey Short Form-36 (SF-36), the Zung Self-Rating Depression Scale (SDS), and the Spielberger State-Trait Anxiety Inventory (STAI)

‡PCS: Physical Component Summary; MCS: Mental Component Summary

reduced motivation $(\mathrm{r}=0.50)$ but only moderately correlated with other subscales of the MFI-20. In general, the scores of the STAI correlated with all five MFI-20 subscale scores. The trait-anxiety score of the STAI had stronger correlations than state-anxiety with the MFI-20 subscale scores (Table S3, Additional file 1).

For the chronically unwell and well groups, depression and anxiety correlated with all five MFI-20 subscales. The bodily pain subscale and the physical component summary scores of the SF-36 did not correlate with the mental fatigue subscale of the MFI-20. Depression, as measured by the SDS index, correlated with all the MFI-20 subscales. The correlations between bodily pain of the SF-36 and activity fatigue (reduced activity or reduced motivation) are not statistically significant (Table S4 and Table S5, Additional file 1).

\section{Discussion}

This study greatly extends previous research with the MFI20 in several ways. The first objective of this study was to assess reliability and validity of the MFI-20 in chronically unwell and well groups identified from metropolitan, urban, and rural populations in the state of Georgia. The MFI-20 was well-accepted in our sample of unwell and well people. Low to moderate inter-item correlations indicated no item redundancy. Corrected item-total correla- tions for all MFI-20 subscales were all in an acceptable range. The MFI-20 item subscales exhibited adequate internal consistency reliability with Cronbach's $\alpha$ coefficients ranging from 0.72 to 0.86 , which is consistent with results from previous studies $[2,17,21,36]$. We found no significant floor/ceiling effects in the whole study sample.

With respect to validity, the results of factor analysis of the MFI-20 in a sample of unwell and well people provide additional support for the five-factor structure of the MFI20 [2]. As previously noted, however, some factors are highly correlated, and several items would have loaded on more than one factor had the paths not been constrained. In addition to forming its own factor component, one of the general fatigue subscale items loaded on the same factor with items of the physical fatigue subscale because it provides information about physical fitness. This general fatigue subscale item may be considered along with the physical fatigue subscale to assess fatigue scores in populations with fatiguing illnesses. The results also showed that a total fatigue summary score is a valid summary score for people with fatiguing illnesses.

In a further examination of known-group comparison for construct validity, all five MFI-20 subscales distinguished clearly between our three study groups. The magnitude of the mean group differences in the MFI-20 subscales is 
greater than the generic minimal clinically important difference (MCID) of two points across the pre- and postradiotherapy comparison and occupational productivity anchor [37]. People with CFS-like illness had several higher fatigue and activity subscale mean scores that were both statistically and clinically significant (an average of three points higher) than those who were chronically unwell but did not have CFS-like illness. These differences were more exaggerated (six points higher, on average) when the CFS-like group was compared to the well group with respect to these subscales. As expected, those who were chronically unwell also had fatigue and activity subscale scores that were both statistically and clinically significant (three points higher than well people).

The MFI-20 subscales exhibited adequate convergent validity with other instruments. The general fatigue subscale of the MFI-20 is highly correlated with the functioning subscales of the SF-36, SDS depression, and the trait anxiety subscale of the STAI. This confirms that the general fatigue subscale represents both physical and psychological aspects of fatigue. Physical fatigue represents the physical sensation related to fatigue, which is validated by the substantial associations with physical functioning, role physical, bodily pain, social functioning, vitality, general health perception, and physical component summary measure. Reduced activity refers to the influence of both physical and psychological factors on the level of activity. Reduced motivation refers to the psychological experience of feeling unable to start an activity [38]. Finally, mental fatigue, which originally measures cognitive functioning such as difficulty concentrating, reflects the "mental health" concept of fatigue, which is validated by the associations with social functioning, mental health, and vitality as well as the mental component summary measure.

Our study showed that sex and age exert effects on several MFI-20 subscales. Compared to males, females had slightly higher mean scores for subscales measuring general fatigue, physical fatigue, and mental fatigue. This confirms previous findings of sex differences in mean scores of fatigue scales $[21,39]$, and age-associated increases in mean scores in physical fatigue, reduced activity, and reduced motivation [18].

We showed that the five MFI-20 subscales were highly correlated with functional impairment, depression, and anxiety in the overall sample. Breslin et al. [40] showed that depression correlated with the general fatigue and mental fatigue subscales of the MFI-20 but not with physical fatigue in patients with chronic obstructive pulmonary disease (COPD). Schwarz et al. [21] showed that fatigue is correlated with hospital anxiety and depression scale (HADS) and the global quality-of-life scale.
Our CFS-like group provides the opportunity to examine the convergent validity of the MFI-20 with other measurements among people with fatiguing illness. In the CFSlike group, additional support for the validity of the MFI20 is provided by the insignificant-to-moderate correlations between the SF-36 subscales and mental fatigue of the MFI-20. This indicates that mental fatigue is only partly measured by the SF-36 among individuals with CFS-like illness. Depression is moderately correlated with several subscales of the MFI-20. We also showed low correlations between state-anxiety of the STAI and general fatigue, physical fatigue, and reduced activity of the MFI20 . Therefore, the additional information provided by the MFI-20 may deepen our insight into functional impairment, depression, and anxiety in fatiguing illnesses.

\section{Strengths and limitations}

The study's strengths include: a rigorous study design with a large, randomly selected sample from a cross-sectional, population-based study of fatiguing illness; and the careful clinical determination of groups, selection of comparison measures, report of reading levels of the instrument, and correction of $\mathrm{p}$-values for multiple testing.

This study has several limitations. Our existing data did not allow us to conduct test-retest reliability of the MFI20. Further studies might be needed to explore test-retest reliability of MFI-20 in fatiguing illness. Another limitation is external validity/generalizability. While the study employed random sampling, the population was limited to an adult population in Georgia and could therefore differ from results that might be obtained from implementing the same study design in other regions due to the effect of regional lifestyle. Nonetheless, previous studies on MFI-20 have not identified the effect of regional lifestyle in their study populations. Our cross-sectional data precluded us from examining responsiveness (ability of the MFI-20 to detect clinically important changes over time) and obviates the possibility of eventually examining responsiveness differences due to treatments. Longitudinal studies are needed to determine minimal clinically important differences (MCIDs) of the MFI-20 subscales in fatiguing illness.

In this study, we applied a 0.01 alpha level of statistical significance to adjust for multiple testing instead of the popular standard level of 0.05 . This increases our confidence in the associations that were determined to be of statistical significance but also increases the risk of failing to reject a false null hypothesis (a Type II error), and so results in less statistical power. However, the statistically significant results observed in this study are of practical significance. For example, the group mean differences in our study are greater than the generic MCID of two points 
in the MFI-20 subscales in Purcell's study [37]. The possibility of a Type II error should, however, be considered.

\section{Conclusions}

This study further demonstrates that the MFI-20 appears to be a valid and reliable measure of chronically unwell and well populations with a stable multidimensional factorial structure. It also suggests that the MFI-20 could indeed be a useful tool for further investigation of generic functional impairment and a complementary diagnostic tool to depression-specific and anxiety-specific instruments in fatiguing illnesses such as chronic fatigue syndrome.

\section{Competing interests}

The authors declare that they have no competing interests.

\section{Authors' contributions}

JML contributed to the conception of the manuscript, had primary responsibility for data processing, statistical analyses, and interpretation of the data, and wrote the manuscript. DJB contributed to intellectual input to data interpretation, streamlining the introduction, and revising the manuscript. EM contributed to data interpretation and critically revised the manuscript. EN contributed to tabulating the results and literature search, and revised the manuscript. RB contributed to intellectual input in the discussion section and revised the manuscript. WCR was Principal Investigator of the source study, collaborating with others in designing the study, writing the protocol, supervising field work, interpretation of the data, and critically revising the manuscript. All authors have read and approved the final manuscript.

\section{Additional material}

\section{Additional file 1}

The supplementary materials include the sex and age-specific norms of five MFI-20 subscales and the convergent validity by three study groups (CFS-like, chronically unwell, and well).

Click here for file

[http://www.biomedcentral.com/content/supplementary/14787954-7-18-S1.DOC]

\section{Acknowledgements}

This study was fully funded by the US Centers for Disease Control and Prevention. The authors would like to acknowledge Drs. James F. Jones and Roumiana S. Boneva of the CDC for their reviews of this manuscript.

\section{References}

I. Lewis G, Wessely S: The epidemiology of fatigue: more questions than answers. I Epidemiol Community Health 1992, 46(2):92-97

2. Smets EM, Garssen B, Bonke B: Manual; Multidimensional Fatigue Inventory. Amsterdam: Medical Psychology, Academic Medical Centre; 1995.
3. Ericsson A, Mannerkorpi K: Assessment of fatigue in patients with fibromyalgia and chronic widespread pain. Reliability and validity of the Swedish version of the MFI-20. Disabil Rehabil 2007, 29(22): 1665-1670.

4. Rahman S, Griffin HJ, Quinn NP, Jahanshahi M: Quality of life in Parkinson's disease: the relative importance of the symptoms. Mov Disord 2008, 23(10): 1428-34.

5. Benedict RH, Wahlig E, Bakshi R, Fishman I, Munschauer F, Zivadinov $R$, Weinstock-Guttman B: Predicting quality of life in multiple sclerosis: accounting for physical disability, fatigue, cognition, mood disorder, personality, and behavior change. J Neurol Sci 2005, 23 I ( I-2):29-34. Epub 2005 Jan 26.

6. Smets EM, Garssen B, Cull A, De Haes JC: Application of the multidimensional fatigue inventory (MFI-20) in cancer patients receiving radiotherapy. $\mathrm{Br}$ J Cancer 1996, 73(2):24I-245.

7. Kennedy SH: Core symptoms of major depressive disorder relevance to diagnosis and treatment. Dialogues in ClinicalNeuroscience 2008, 10:27I-7.

8. Bakshi R, Shaikh ZA, Miletich RS, Czamecki D, Dmochowski J, Henschel $\mathrm{K}$, Janardhan V, Dubey N, Kinkel PR: Fatigue in multiple sclerosis and its relationship to depression and neurologic disability. Multiple Sclerosis 2000, 6:18I-I85.

9. Kroencke DC, Lynch SG, Denny DR: Fatigue in multiple sclerosis: relationship to depression, disability, and disease pattern. Multiple Sclerosis 2000, 6: 131-136.

10. Pittion-Vouyovitch S, Debouverie M, Guillemin F, Vandenberghe N, Anxionnat $R$, Vespignani $H$ : Fatigue in multiple sclerosis is related to disability, depression and quality of life. Journal of Neurological Sciences 2006, 243:39-45.

II. Addington AM, Gallo JJ, Ford DE, Eaton WW: Epidemiology of unexplained fatigue and major depression in the community: The Baltimore ECA Follow-up, 198I-1994. Psychological Medicine 200I, 31:1037-1044.

12. Fuller-Thomson E, Nimigon J: Factors associated with depression among individuals with chronic fatigue syndrome: findings from a nationally representative survey. Fam Pract 2008, 25(6):4I4-22. Epub 2008 Oct 3

13. Nater U M, Lin J-M S, Maloney E M, Jones J F, Tian H, Boneva R S, Raison C L, Reeves W C, Heim C: Psychiatric Comorbidity in Persons With Chronic Fatigue Syndrome Identified From the Georgia Population. Psychosom Med 2009, 7 I(5):557-65. Epub 2009 May 4.

14. Roy-Byrne P, Afari N, Ashton S, Fishcer M, Goldberg J, Buckwald D: Chronic fatigue and anxiety/depression: a twin-study. British Journal of Psychiatry 2002, 180:29-34.

15. Smets EM, Garssen B, Bonke B, De Haes JC: The multidimensional fatigue inventory (MFI) psychometric qualities of an instrument to assess fatigue. Journal of Psychosomatic Research 1995, 39:3I5-325

16. Visser MR, Smets EM: Fatigue, depression and quality of life in cancer patients: how are they related? Support Care Cancer 1998, 6(2): $101-108$.

17. Hagelin CL, Wengström $Y$, Runesdotter S, Fürst CJ: The psychometric properties of the Swedish Multidimensional Fatigue Inventory MFI-20 in four different populations. Acta Oncol 2007, 46(I):97-104.

18. Gentile S, Delarozière JC, Favre F, Sambuc R, San Marco JL: Validation of the French 'multidimensional fatigue inventory' (MFI 20). Eur J Cancer Care (Engl) 2003, I 2(I):58-64.

19. Dekkers OM, Biermasz NR, Smit JW, Groot LE, Roelfsema F, Romijn JA, Pereira AM: Quality of life in treated adult craniopharyngioma patients. Eur J Endocrinol 2006, I54(3):483-489.

20. Jansen AJ, Essink-Bot ML, Beckers EA, Hop WC, Schipperus MR, Van Rhenen DJ: Quality of life measurement in patients with transfusion-dependent myelodysplastic syndromes. Brit J Haem 2003, I 2 I:270-274.

21. Schwarz $R$, Krauss $O$, Hinz A: Fatigue in the general population. Onkologie 2003, 26: I40-I44.

22. Schneider RA: Reliability and validity of the Multidimensional Fatigue Inventory (MFI-20) and the Rhoten Fatigue Scale among rural cancer outpatients. Cancer Nursing 1998, 2I(5):370-373.

23. Schneider RA: Preliminary data on the Multidimensional Fatigue Inventory-20 from female caregivers of male hemodialysis patients. Psychol Rep 200I, 88(3 Pt I):699-700. 
24. Reeves WC, Jones JJ, Maloney EM, Heim C, Hoaglin DC, Boneva RS, Morrissey M, Devlin R: Prevalence of chronic fatigue syndrome in metropolitan, urban, and rural Georgia. Population Health Metrics 2007, 8(5):5.

25. Ware JE, Sherbourne CD: The MOS 36-item short-form health survey (SF-36). Conceptual framework and item selection. Medical Care 1992, 30:473-483.

26. Ware JE: SF-36 health survey update. Spine 2000, 25:3 I30-3। 39 .

27. Zung W WK: A rating instrument for anxiety disorders. Psychosomatics 197I.

28. Spielberger CD: Manual for the State-Trait Anxiety Inventory (STAI). Palo Alto, CA: Consulting PsychologistsPress; 1983.

29. Jastak S, Wilkinson G: Wide Range Achievement Test-Revisited. Wilmington, Delaware: Jastak Associates Inc; 1984.

30. Nunnally JC, Bernstein IH: Psychometric theory. 3rd edition. New York: McGraw-Hill; 1994.

31. Cronbach LJ: Coefficient alpha and the internal structure of tests. Psychometrika 195I, 16:297-334.

32. Terwee CB, Bot SD, de Boer MR, Windt DA van der, Knol DL, Dekker J, Bouter LM, de Vet HC: Quality criteria were proposed for measurement properties of health status questionnaires. J ClinEpidemiol 2007, 60(1):34-42. Epub 2006 Aug 24.

33. Nunnally JC: Psychometric testing. 2nd edition. New York: McGraw-Hill; 1978.

34. Zeller RA, Carmines EG: Measurement in the social sciences: the link between theory and data. London: Cambridge University Press; 1979.

35. Cohen J: Statistical power analysis for the behavioral sciences. 2nd edition. New Jersey: Erlbaum; 1988.

36. Stein KD, Jacobsen PB, Blanchard CM, Thors C: Further validation of the multidimensional fatigue symptom inventory-short form. J Pain Symptom Manage 2004, 27(I): I4-23.

37. Purcell A, Fleming J, Bennett S, Burmeister B, Haines T: Determining the minimal clinically important difference criteria for the Multidimensional Fatigue Inventory in a radiotherapy population. Support Care Cancer 2009 in press.

38. de Jong N, Candel MI, Schouten HC, Abu-Saad HH, Courtens AM: Course of mental fatigue and motivation in breast cancer patients receiving adjuvant chemotherapy. Ann Oncol 2005 16(3):372-82. Epub 2005 Jan 27.

39. Watt T, Groenvold M, Bjorner JB, Noerholm V, Rasmussen NA, Bech $P$ : Fatigue in the Danish general population. Influence of sociodemographic factors and disease. J Epidemiol Community Health 2000, 54( I I ):827-833.

40. Breslin E, Schans C Van der, Breukink S, Meek P, Mercer K, Volz W, Louie S: Perception of fatigue and quality of life in patients with COPD. Chest 1998, I 14:958-964.

Publish with Bio Med Central and every scientist can read your work free of charge

"BioMed Central will be the most significant development for disseminating the results of biomedical research in our lifetime. "

Sir Paul Nurse, Cancer Research UK

Your research papers will be:

- available free of charge to the entire biomedical community

- peer reviewed and published immediately upon acceptance

- cited in PubMed and archived on PubMed Central

- yours - you keep the copyright
BioMedcentral 